\title{
La Universidad Nacional de Costa Rica y las sedes regionales como mecanismo de inclusión social
}

\author{
National University of Costa Rica and Its Regional \\ Campuses as a Mechanism for Social Inclusion
}

\author{
Ileana Schmidt-Fonseca \\ Universidad Nacional \\ Heredia, Costa Rica \\ Ileana.schmidt.fonseca@una.cr
}

Recibido: 09/ 22/2014 Aceptado: 06/29/2016

Resumen: La experiencia de sistematizar los procesos de gestión académica, desarrollada en el Programa Académico Interdisciplinario de la Región Huetar Norte y Caribe de la UNA, con el fin de comprender si las acciones realizadas han alcanzando la población que menos oportunidades tiene de acceder a la educación superior, y así cumplir con los principios básicos de la misión institucional; arrojó, en los resultados, que se atiende un 50\% más del promedio institucional de estudiantes de colegios rurales, CINDEAS o telesecundarias, es decir, de colegios clasificados estrato $3 \mathrm{y}$, además, un $89 \%$ de esta población requiere de algún tipo de ayuda socioeconómica que le permita estudiar. Se inicia, entonces, un proceso de revisión de las estadísticas ofrecidas por el Sistema de Estadísticas Estudiantiles y Vida Estudiantil entre los años 2009 al 2013, con el fin de compararlos con los promedios institucionales, y saber si la acción académica desarrollada por la UNA en las regiones es un mecanismo eficiente de inclusión social, como en un principio evidencian los resultados obtenidos en el Programa. Resultó que en las sedes regionales se atiende un prome- 
dio $25 \%$ superior al promedio institucional de estudiantes de estrato 3 , que es una población estudiantil cuyas necesidades de apoyo socioeconómico, también superan el promedio institucional. Esto nos permite concluir que uno de los mecanismos de asegurar inclusión social en la UNA es su acción a través de las sedes regionales.

Palabras claves: inclusión social, educación superior, regiones.

\begin{abstract}
The Interdisciplinary Academic Program of the National University is developing the experience of systematizing the academic management processes in the Huetar Norte and Caribbean Region in order to understand whether the actions taken have reached the population with fewer opportunities of access to higher education; and thus to comply with the basic principles of the institutional mission. The results of the experience showed that $50 \%$ more of the institutional average of students from rural schools, CINDEAS, or telesecundaria (distance education secondary school), i.e., schools classified as stratum 3, were covered; besides, $89 \%$ of this population requires some type of socio-economic assistance to give them the opportunity to study. Therefore, a reviewing process of the statistics offered by the Student Statistics System and Student Life between the years 2009 to 2013 was launched to compare them with the institutional averages, and to know whether the academic action the National University developed in the regions is an efficient mechanism for social inclusion, as shown in the results initially obtained in the program. It turned out that, in the regional campuses, the average of coverage was $25 \%$ greater than the institutional average of students of stratum 3 , a student population with socio-economic needs exceeding the institutional average as well. This allowed us to conclude that one of the mechanisms to ensure social inclusion at the National University is its action through the regional campuses.
\end{abstract}

Keywords: social inclusion, higher education, regions.

\title{
La universidad nacional en las regiones
}

La Universidad Nacional De Costa Rica es una entidad de educación superior muy joven, constituida el 15 de febrero de 1973, mediante la Ley 5182, la cual transforma las Escuelas Normales de Costa Rica y la Escuela Normal Superior, hasta el momento las responsables de formar los educadores del país, en Universidad Nacional de Costa Rica, y que entra en operación el 14 de marzo de ese mismo año.

En ese momento existían tres: La Escuela Normal en Heredia, La Escuela Normal en San Isidro de El General y la Escuela Normal en Nicoya. Así, entonces, nace la Universidad Nacional de Costa Rica, cuya sede central se 
establece en Heredia y sus dos instancias regionales: La Sección Regional Brunca y la Sección Regional Chorotega.

En el caso de la Sección Regional Brunca, inicia sus funciones con la carrera de educación; oferta actualmente cinco carreras de grado, entre sus dos campus: Pérez Zeledón y Coto, y en el año 1993 fue declarada Sede Región Brunca.

La Sección Regional Chorotega, por su parte, cuenta actualmente con una oferta académica de seis carreras, entre sus dos campus: Liberia y Nicoya. En el año 1998, fue transformada como Sede Regional Chorotega.

En el marco de la celebración del XXXV Aniversario de su fundación, en el año 2008, y siguiendo con sus principios constituyentes de orientar su quehacer hacia aquellos sectores menos favorecidos de la sociedad costarricense, tiene la oportunidad de expandir sus fronteras abriendo un campus universitario en la Región Huetar Norte y Caribe, mediante el establecimiento de un programa denominado Programa Académico Interdisciplinario Región Huetar Norte y Caribe.

El Programa Académico Interdisciplinario de la Región Huetar Norte y Caribe fue declarado Sección Regional, en julio del 2014, y oferta para el año 2015, cuatro carreras a nivel de grado y una a nivel de pregrado.

\section{La educación como motor de desarrollo de las regiones}

El rol de la educación en la sociedad, según lo plantea Renato Opertti (2008), en Inclusión educativa: El camino al futuro, desde una visión holística, tiene cinco dimensiones centrales, las cuales se resumen en:

- La educación como factor responsable de sentar las bases empíricas y conceptuales para forjar una ciudadanía democrática.

- La educación como política social y económica clave que visualiza la justicia y la competitividad, la equidad y la calidad para forjar condiciones y oportunidades para un mejor bienestar.

- La educación como facilitadora y generadora de oportunidades que contribuye a la reducción de la pobreza y marginalidad con una visión de largo plazo.

- La educación como factor crucial que asegure la integración digna, proactiva, inteligente y productiva de sociedades nacionales en un mundo globalizado, aprovechando las oportunidades y superando los obstáculos. 
- La educación como modo de contribuir a establecer bases sólidas de integración social y cultural que aborde decididamente la reducción de las enormes brechas de disparidad que mayormente se vinculan a factores culturales, sociales, económicos, de género, etnia y migración.

Es decir, el rol de la educación en la sociedad busca el crecimiento económico sostenible y justa distribución de oportunidades en pro de mejorar la calidad de vida para todas las personas integrantes de la sociedad.

En Costa Rica, en la última clasificación del del Estado de la Nación (2013), según el índice de desarrollo humano (IDH), que se calcula sobre 3 indicadores que incluye: pobreza y pobreza extrema, acceso a salud y educación de calidad, y bienestar, se ubican los distritos de las regiones periféricas del país (Brunca, Chorotega, Huetar Norte, Huetar Caribe y Pacifico Central) con los índices más bajos. Esto es, en estas regiones es donde peor acceso hay a la educación y salud; se presenta más la pobreza y pobreza extrema y se vive con menos bienestar, contrario, en general, a los distritos de la Gran Área Metropolitana (GAM). Por tanto, en las regiones periféricas del país el acceso a educación es vital para asegurar la oportunidad de que su población tenga acceso a una vida mejor.

\section{La educación un derecho para todas las personas}

Rosa María Torres (2006, p. 43) destaca que: “el derecho a la educación supone el desarrollo de una educación en sintonía con el tiempo, las realidades y las necesidades de aprendizaje de las personas en cada contexto y momento".

En nuestro caso, derecho a la educación supondría acceso a educación superior de calidad, contextualizado en la realidad cotidiana, cerca de su entorno natural, que considere sus características particulares tales como las culturales o sociales y las necesidades de aprendizaje especiales.

\section{La Universidad Nacional y su política de inclusión}

Se entiende inclusión como "el derecho a una educación que implica equivalentes oportunidades de aprendizaje en diferentes tipos de escuelas independientemente de sus antecedentes sociales y culturales y de sus diferencias en las habilidades y capacidades." (Opertti, 2008, p. 11). No solo como la oportunidad para todas las personas sin distingo de condición social, cultural, de habilidades o capacidades al acceso, sino además, a la permanencia. 
La exclusión en la educación no solo debe verse como la falta de acceso a esta por cualquier causa, sino también la sufren quienes, habiendo accedido al sistema educativo, se ven expulsados de este porque no considera sus diferencias en condición social, cultural o de accesibilidad. Por esto, hablar de una política inclusiva es hablar de una política que no solo permita el acceso, sino que además, favorezca la permanencia.

Como ejemplo, en la Universidad Nacional encontramos el sistema de estratificación y tipificación en su proceso de admisión, una vez que se cuenta con las notas de la prueba de aptitud académica, la de aptitud específica si la hubiese, y el promedio de notas del ciclo diversificado, se aplica una fórmula que favorece a aquellos cuyas oportunidades a educación de calidad se ven disminuidas por sus condiciones sociales, económicas y culturales.

Según se describe en el Manual de Procedimiento de Admisión (2013), dicho sistema considera dos tipos de indicadores, a saber:

Indicador técnico (nota de admisión). Se utiliza como predictor del rendimiento académico. Está compuesto por la nota obtenida en la prueba de aptitud académica, el promedio de notas del ciclo diversificado y la nota de la prueba específica, cuando corresponda.

Indicador social. Se utiliza para estimar las diferencias de tipo social, económico y académico que inciden sobre el rendimiento de los estudiantes y las estudiantes en sus estudios.

Las variables disponibles que se consideran para estimar este indicador social son las siguientes:

Modalidad de estudio (colegios académicos, colegios técnicos o artísticos, bachillerato por madurez, telesecundarias, bachillerato a distancia, plan de estudios para la educación de jóvenes y adultos, nuevas oportunidades educativas para jóvenes, extranjeros, CINDEAS e IPEC).

Horario del colegio de procedencia (diurno o nocturno).

Tipo de colegio (privado, público, privado subvencionado, científicos, humanísticos).

Ubicación geográfica del colegio. 
Para aplicar lo anterior, quienes aspiren a ingresar a la Universidad se agrupan en estratos, con el objetivo de que compitan dentro de un grupo con características similares. Se parte del hecho de que existen diferencias en cuanto a las condiciones académicas de cada postulante, de acuerdo con las variables anteriormente citadas, lo que se refleja en las notas de cada estrato.

Actualmente la Universidad Nacional diferencia tres estratos:

Estrato 1: Colegios privados y privados subvencionados

Estrato 2: Colegios públicos académicos y técnicos profesionales diurnos y nocturnos

Estrato 3: Colegios rurales, telesecundarias, CINDEAS, sistema abierto diurnos y nocturnos

Sistema de Becas. Este es otro elemento relevante en la línea inclusiva de la UNA. Permite a jóvenes de escasos recursos o situaciones especiales mantenerse en la Universidad. Estas incluyen:

Becas parciales, desde la 1 a la 9; diferentes porcentajes de descuento en el costo del creditaje.

Becas totales y de ayuda socio-económica, si así se requiere: Beca 10 , Beca Omar Dengo y Beca Luis Felipe.

Becas para incentivos a mejores promedios o participación artística o deportiva.

\section{Metodología}

Este estudio se enmarca en una investigación descriptiva que pretende, simplemente, con una revisión de los resultados encontrados, conocer el estado del fenómeno de inclusión social en la Universidad desde la dimensión de accesibilidad para las clases menos privilegiadas y de la ruralidad del país.

Se analizaron los datos de I Ingreso de la Universidad Nacional de los años 2009 al 2013, tanto por tipos de estrato de origen como por su condición socioeconómica, para tener un rasgo y características reales del tipo de estudiantes que ingresa a la Universidad en las sedes ubicadas en la Gran Área Metropolitana y contrastarlos con los rasgos y características de la población estudiantil que ingreso en la sedes y secciones ubicadas en las regiones periféricas del país.

Esta información fue recopilada de los Sistemas de Estadísticas de Registro y de la información que procesan los funcionarios de la Vicerrectoría de Vida Estudiantil, en la Dirección de Bienestar. 


\section{Análisis de resultados}

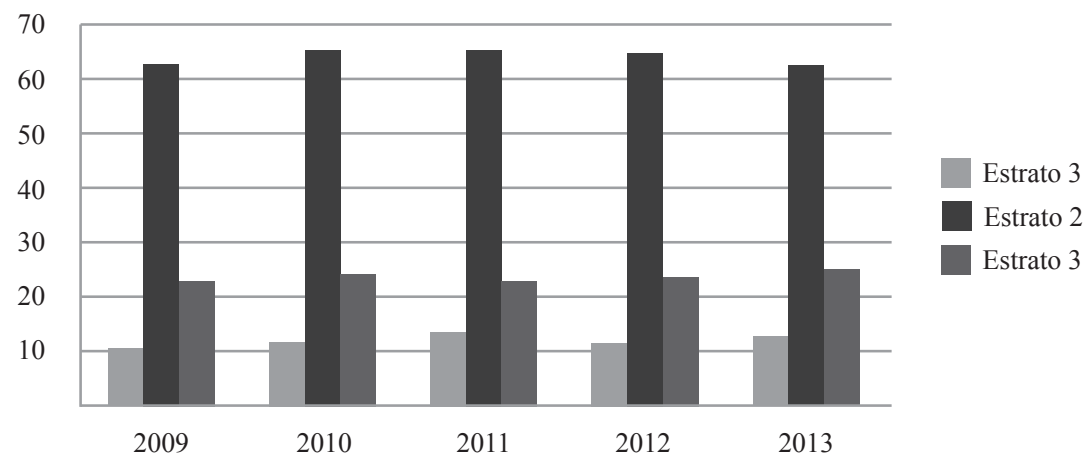

Figura 1. Estudiantes de nuevo ingreso por estratos en sedes de la GAM 2009-2013. Sistema de Estadísticas de la Universidad Nacional. 2014.

Entre los años 2009-2013, en la GAM el estudiantado de I ingreso proveniente del estrato tres se mantuvo entre un $10 \%$ y un $13 \%$ del total de estudiantes en esos años. Más del $60 \%$ pertenece al estrato 2 y solo el $20 \%$ pertenece al estrato 1 .

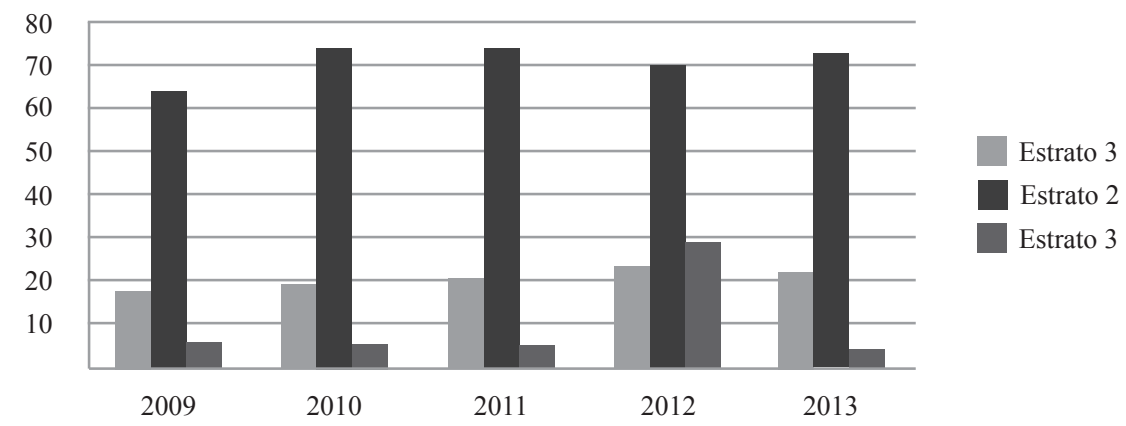

Figura 2. Estudiantes de primer ingreso por estratos en las sedes regionales 2009- 2013. Sistema de Estadísticas de la Universidad Nacional. 2014. 
Revista Universidad en Diálogo • Vol. 6, N. 2, Julio-diciembre 2016, pp. 193-203

ISSN 2215-2849 • EISSN: 2215-4752

DOI: http://dx.doi.org/10.15359/udre.6-2.11

En sedes y secciones regionales entre los años 2009 y 2013, un $18 \%$ a un $22 \%$ de estudiantes pertenece al estrato 3 , un promedio del $70 \%$ son estudiantes de estrato 2 y alrededor de un $5 \%$ pertenece al estrato 1 .

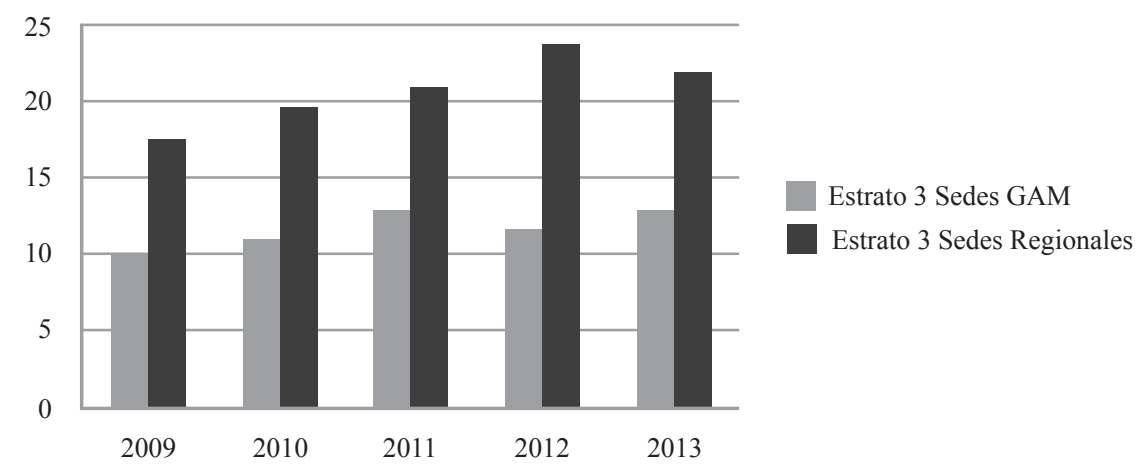

Figura 3. Estudiantes de primer ingreso de estrato 3 según tipo de sede 20092013. Sistema de Estadísticas de la Universidad Nacional. 2014.

Como se puede apreciar en la figura 3 , donde se comparan los estudiantes de primer ingreso de estrato 3, según tipo de sede en los años 2009 al 2013, el ingreso de estudiantes de estrato 3 a sedes y secciones regionales superan hasta en un $50 \%$ el porcentaje de ingreso de estudiantes de estrato 3 en las sedes del Gran Área Metropolitana.

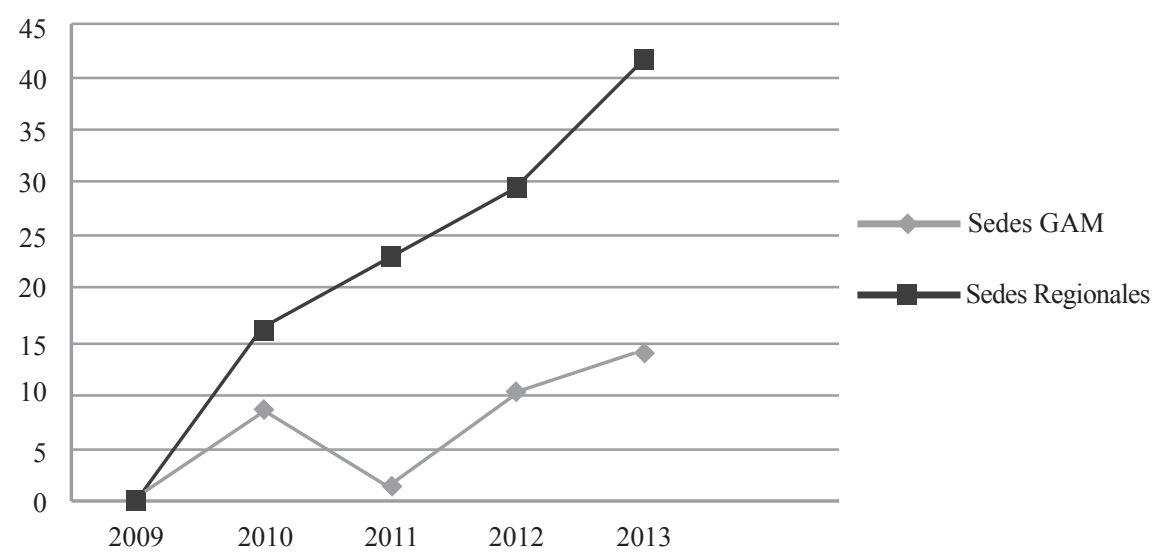

Figura 4. Crecimiento acumulado de estudiantes de primer ingreso según tipo de sede 2009-2013. Sistema de Estadísticas de la Universidad Nacional. 2014. 
En la figura 4 se resalta el crecimiento de estudiantes de primer ingreso a las sedes y secciones regionales y a sedes de la Gran Área Metropolitana. Los estudiantes de sedes y secciones regionales incrementaron su porcentaje de estudiantes de primer ingreso en más de un $40 \%$ en los últimos 5 años, contra un crecimiento del 15\% máximo en las sedes de la GAM.

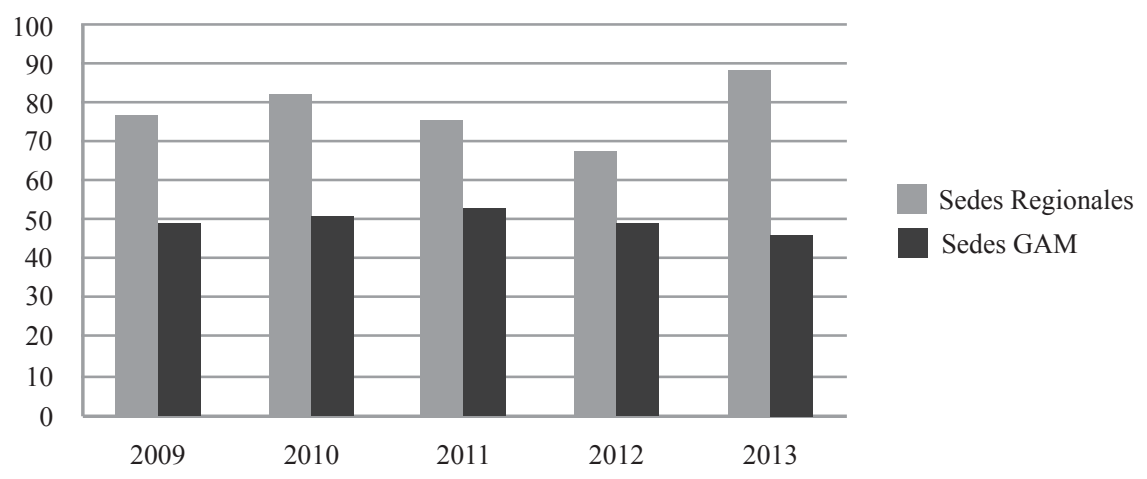

Figura 5. Porcentaje de estudiantes de primer ingreso que solicitan beca según tipo de sede. Bienestar Estudiantil Vicerrectoría de Vida Estudiantil de la Universidad Nacional. 2014.

Entre los años 2009 al 2013, en las sedes y secciones regionales más de un $75 \%$ de los estudiantes de primer ingreso hacen solicitud de beca para cursar sus estudios en la Universidad. En las sedes de la Gran Área Metropolitana este porcentaje es de un 50\% de la población de primer ingreso (ver figura 5).

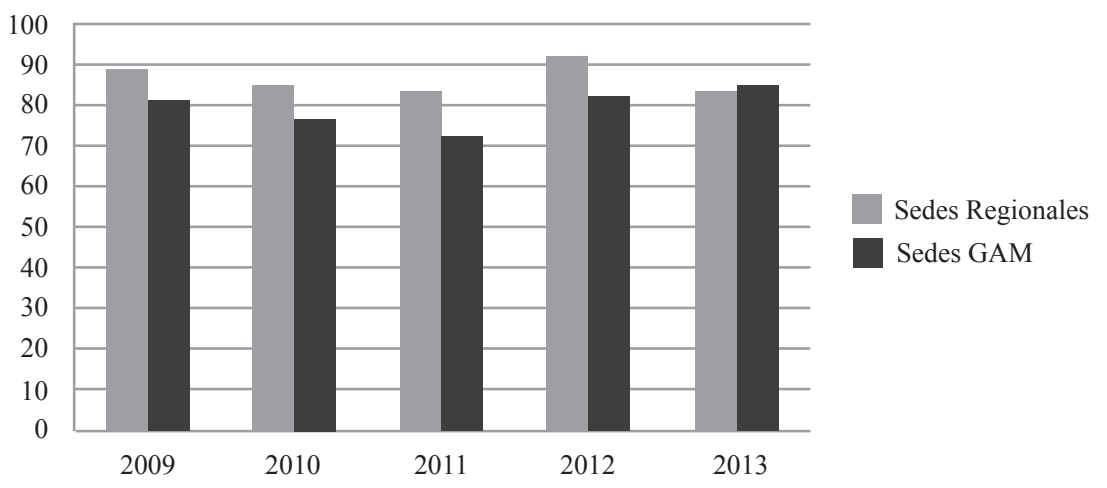

Figura 6. Porcentaje de solicitantes de primer ingreso que recibieron algún tipo de beca según tipo de sede. Bienestar Estudiantil Vicerrectoría de Vida Estudiantil de la Universidad Nacional. 2014. 
En la figura 6 se puede apreciar como del total de solicitudes de becas hwechas entre los años 2009 al 2013, más del 80\% de los estudiantes de primer ingreso de sedes y secciones regionales reciben algún tipo de beca, igualmente un poco menos de ese $80 \%$ de solicitudes de becas en estudiantes de sedes de la GAM, reciben algún tipo de ayuda socio económica.

\section{Conclusiones}

- Las secciones y sedes regionales atienden un 50\% más de estudiantes de estrato 3 que la sedes de la Gran Área Metropolitana.

- La población de estudiantes de primer ingreso de los últimos 5 años que se atiende en las sedes regionales son $95 \%$ provenientes de estrato 2 y 3 . En las sedes de la Universidad de la Gran Área Metropolitana esta población se compone de un $80 \%$.

- Aproximadamente el $80 \%$ de estudiantes de primer ingreso a sedes y secciones regionales solicita apoyo para poder realizar sus estudios. En la sede central un $50 \%$ de los estudiantes de primer ingreso hace solicitud para poder realizar estudios.

- El $80 \%$ de los estudiantes de primer ingreso que hace solicitud a becas o ayudas socioeconómicas en la Universidad Nacional recibe algún tipo de beca, tanto en las instancias regionales como en las sedes de la GAM.

- Las sedes y secciones regionales son el brazo de la Universidad en las regiones donde más se requiere formación, y en donde menos oportunidades tiene la juventud de continuar con sus estudios superiores.

- Las sedes y secciones regionales de la Universidad Nacional permiten mayor acceso a estudios superiores a estudiantes de estrato 3, es decir, estudiantes provenientes de los sistemas de educación pública con mayor desventaja, estudiantes de zonas rurales y de menor desarrollo.

- La mayoría de estudiantes de primer ingreso de las sedes y secciones regionales son estudiantes que requieren ayuda socio económica para poder realizar sus estudios.

- Las prácticas de atracción y admisión apoyan el acceso a la educación de jóvenes de todos los estratos sociales, y ofrece un sistema de apoyo socioeconómico, que permite la permanencia, en el sistema, de aquellas personas con características diferentes sociales, culturales y en sus habilidades y capacidades, las que se advierten, mayoritariamente, en la instancias regionales, por ser estas las que, además, permiten ese acceso contextualizado y cerca del entorno natural de los que menos oportunidades tienen. 


\section{Referencias}

Programa Estado de la Nación. (2013). Decimonoveno Informe Estado de la Nación en Desarrollo Humano Sostenible. San José: Programa Estado de la Nación

Universidad Nacional de Costa Rica. (2013). Procedimientos de admisión para el ingreso a las carreras de grado de la Universidad Nacional. Heredia, Universidad Nacional.

Opertti, R. (2008). Inclusión educativa: El camino del futuro. OIE-UNESCO. Recuperado de http://www.ibe.unesco.org/fileadmin/user_ upload/COPs/News_documents/2007/0710PanamaCity/Documento_Inclusion_Educativa.pdf

Torres, $\bar{M}$. R. (2006). Derecho a la educación es más que el acceso a la escuela. En L. M. Naya y P. Dávila (coord.), EL derecho a la educación en un mundo globalizado (Vol. I, pp. 43-58). Donostia: Espacio Universitario Erein. 